\title{
Desain Jaringan WLAN Berdasarkan Cakupan Area dan Kapasitas
}

\author{
Zawiyah Saharuna ${ }^{1}$, Rini Nur ${ }^{2}$ \\ ${ }^{1,2}$ Jurusan Teknik Elektro, Politeknik Negeri Ujung Pandang \\ ${ }^{1,2}$ Jalan Perintis Kemerdekaan KM 10, Tamalanrea, Makassar, 90245 \\ Email korespondensi : wia.saharuna@gmail.com
}

Dikirim 29 Oktober 2016, Direvisi 10 November 2016, Diterima 11 November 2016

\begin{abstract}
Abstrak - Penelitian ini mengangkat kasus pada kampus 2 Politeknik Negeri Ujung Pandang (PNUP) yang belum memiliki fasilitas jaringan WLAN, padahal pemanfaatannya sudah dimulai pada awal tahun ajaran 2015/2016. Berdasarkan kondisi tersebut, maka dibuat desain jaringan WLAN yang mempertimbangkan cakupan area dan kapasitas. Hasil penelitian menunjukkan bahwa desain jaringan WLAN berdasarkan cakupan area dibutuhkan 15 buah Access Point untuk Jurusan Teknik Elektro (JTE), 20 buah Access Point untuk Jurusan Akuntansi (JAK), dan 19 buah Access Point untuk Jurusan Administrasi Niaga (JAN). Sedangkan untuk desain jaringan WLAN berdasarkan cakupan area dan kapasitas dibutuhkan 20 buah Access Point untuk JTE, 25 buah Access Point untuk JAK, dan 25 buah Access Point untuk JAN. Hasil ini menunjukkan bahwa dalam perancangan penempatan Access Point pada kampus 2 PNUP sebaiknya mempertimbangkan cakupan area dan kapasitas, karena rancangan yang mempertimbangkan cakupan area saja hanya dapat memenuhi $77,00 \%$ kebutuhan Access Point .
\end{abstract}

Kata kunci - WLAN, cakupan area, kapasitas.

Abstract - This study was conducted in Campus 2 Politeknik Negeri Ujung Pandang (PNUP) which doesn't have a wireless network infrastructure, while already used since the academic year of 2015/2016. Based on such condition, we proposed a design of wireless network which considers the coverage area and capacity. The results showed that the design of wireless network based on coverage area required 15 units Access Point for Jurusan Teknik Elektro (JTE) , 20 units Access Point for Jurusan Akuntansi (JAK), and 19 units Access Point for Jurusan Administrasi Niaga (JAN). While for the design of wireless networks based on coverage area and capacity required 20 units Access Point for JTE, 25 units Access Point for JAK, and 25 units Access Point for JAN. The results indicate that the design of the Access Point placement on Campus 2 PNUP should consider the coverage area and capacity, due to the design that only considers the coverage area can only meet $77.00 \%$ the need of Access Point.

Keywords - WLAN, coverage area, capacity.

\section{PENDAHULUAN}

Jaringan wireless atau dikenal juga dengan jaringan tanpa kabel (nirkabel) sangat efektif dan efisien digunakan untuk mencukupi kebutuhan akses internet. Hal ini dikarenakan adanya proses instalasi yang mudah, biaya perawatan yang murah, ketersediaan jalur yang tak terbatas, serta tingkat fleksibilitas yang tinggi [1].

Jaringan wireless pada suatu area memiliki karakteristik yang berbeda dengan area lain, sehingga memerlukan perlakuan yang berbeda pula. Perbedaan terjadi karena adanya perbedaan struktur bangunan, jenis-jenis penghalang seperti tembok beton, dinding yang terbuat dari bahan kaca maupun kayu, dan keberadaan furniture. Faktor-faktor tersebut akan memberikan pengaruh yang berbeda bagi pancaran radio dari perangkat Access Point (AP), begitu juga dengan penghalang yang bersifat sementara seperti keberadaan manusia. Hal ini menjadikan propagasi radio dalam gedung atau ruangan menjadi susah untuk diprediksi. Keberadaan berbagai penghalang dapat menimbulkan sinyal redaman yang akan mempengaruhi cakupan area dari Access Point [2].

Ketika mendesain jaringan wireless atau WLAN tidak cukup dengan mempertimbangkan cakupan area saja, tetapi faktor kapasitas dari perangkat Access Point juga harus diperhitungkan. Kapasitas akan sangat dipengaruhi oleh jumlah dan kualitas perangkat pengguna yang terhubung ke jaringan, serta jenis aplikasi yang banyak diakses oleh pengguna.

Pada penelitian [3] mengatakan bahwa prediksi propagasi dan teknik pengukuran nirkabel adalah ide dibalik suksesnya penyebaran jaringan indoor Wireless Local Area Network (WLAN). Oleh karena itu, solusi yang diusulkan untuk memonitor dan 
merencanakan WLAN standar IEEE $802.11 \mathrm{a} / \mathrm{b} / \mathrm{g} / \mathrm{n}$ adalah berdasarkan prediksi propagasi dan teknik pengukuran dengan visualisasi kontur berwarna. Prediksi sinyal radio atau perencanaan kerja didasarkan pada model teoritis, sedangkan metode pengukuran dan pemantauan didasarkan pada model empiris. Visualisasi akan menunjukkan hasil pemantauan WLAN dan perencanaan kerja berdasarkan efek propagasi sinyal wireless dari beberapa lantai bangunan. Perangkat eksperimen menggunakan dua band frekuensi yaitu $2,4 \mathrm{GHz}$ dan $5 \mathrm{GHz}$ untuk AP tipe $802.11 \mathrm{n}$, frekuensi $2,4 \mathrm{GHz}$ untuk tipe $802.11 \mathrm{~g}$, dan laptop sebagai penerima sinyal wireless.

Selanjutnya, pada [4] melakukan penelitian yang sama dengan lokasi penelitian gedung PPTIK Universitas Brawijaya. Dua model propagasi nirkabel, yaitu model empiris dan teoritis yang terkait dengan optimasi cakupan area, overlapping channel dan kinerja jaringan nirkabel. Optimasi dari perencanaan jaringan Wi-Fi menghasilkan rata-rata RSSI mencapai $-40 \mathrm{dBm}$ sampai $-55 \mathrm{dBm}$, power 17-18 dBm, dan kanal yang diterapkan adalah kanal 1 sampai 11 secara non overlapping pada desain jaringan yang terdiri dari banyak Access Point secara berdekatan. Hasil optimasi tersebut tergambar pada topologi baru yang disertai dengan display contour dan tersebar diseluruh area.

Penelitian [5] melanjutkan penelitian [4] dengan membuat perencanaan jaringan high performance wireless. Pada penelitian tersebut dipertimbangkan cakupan sinyal Access Point. Untuk cakupan area, diperoleh range nilai RSSI -40 sampai $-55 \mathrm{dBm}$, power Access Point untuk area $72 \mathrm{~m}^{2}$ menggunakan $18 \mathrm{dBm}$, dan channel frekuensi diatur dari channel 1 sampai 11 sehingga tidak terjadi overlapping channel.

Penelitian ini mengangkat kasus pada Kampus 2 Politeknik Negeri Ujung Pandang (PNUP) yang belum memiliki fasilitas jaringan WLAN, padahal pemanfaatannya sudah dimulai pada awal tahun ajaran 2015/2016. Saat ini kampus 2 PNUP memiliki empat gedung yang terdiri dari gedung Jurusan Teknik Elektro (JTE), gedung Jurusan Akuntansi (JAK), gedung Jurusan Administrasi Niaga (JAN), dan gedung Auditorium.

Untuk membangun jaringan WLAN pada Kampus 2 PNUP tentunya harus disertai dengan perencanaan yang matang. Faktor-faktor seperti kebutuhan pengguna, penentuan posisi Access Point, dan konfigurasinya harus dipertimbangkan dalam perencanaan, sehingga dapat meminimalkan permasalahan yang timbul ketika diimplementasikan secara langsung.

Oleh karena itu, penelitian ini mempunyai tujuan untuk mendesain jaringan WLAN pada Kampus II PNUP berdasarkan cakupan area dan kapasitasnya.

\section{METODOLOGI PENELITIAN}

Tahapan-tahapan dalam desain jaringan WLAN berdasarkan cakupan area dan kapasitas pada gedung Jurusan Teknik Elektro (JTE), Jurusan Akuntansi (JAK), dan Jurusan Administrasi Niaga (JAN) secara garis besar dijelaskan pada Gambar 1 .

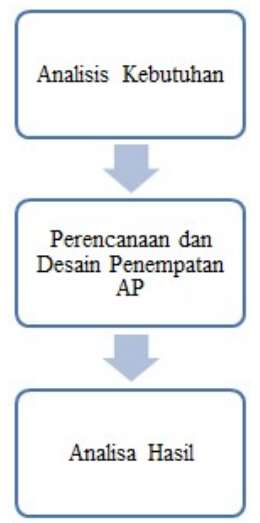

Gambar 1. Tahapan-Tahapan Perancangan Penempatan AP

Tahapan perancangan penempatan Access Point dimulai dengan melakukan analisis terhadap kebutuhan pengguna. Pada tahapan ini diperoleh hasil seperti pada Tabel 1 dan Tabel 2 .

\begin{tabular}{|c|c|c|c|c|}
\hline $\begin{array}{c}\text { Model } \\
\text { Perangkat }\end{array}$ & $\begin{array}{c}\text { Radio } \\
\text { Wifi }\end{array}$ & Channel & $\begin{array}{c}\text { Power } \\
\text { Transmit }\end{array}$ & $\begin{array}{c}\text { Max Data } \\
\text { Rate }\end{array}$ \\
\hline Netbook & $\begin{array}{c}802.11 \mathrm{n} \\
1 \times 2: 2\end{array}$ & $\begin{array}{c}2,4 \mathrm{GHz} \\
1-11\end{array}$ & $\begin{array}{l}11-17 \\
\mathrm{dBm}\end{array}$ & $\begin{array}{c}72 \text { Mbps } \\
\text { (Up) } \\
144 / 300 \\
\text { Mbps } \\
\text { (down) }\end{array}$ \\
\hline Laptop & $\begin{array}{c}802.11 \mathrm{n} \\
2 \times 2: 2\end{array}$ & $\begin{array}{c}2,4 \mathrm{GHz} \\
1-11\end{array}$ & $\begin{array}{l}17-20 \\
\mathrm{dBm}\end{array}$ & $144 \mathrm{Mbps}$ \\
\hline $\begin{array}{l}\text { Smart } \\
\text { phone }\end{array}$ & $\begin{array}{c}802.11 \mathrm{n} \\
1 \times 1: 1\end{array}$ & $\begin{array}{c}2,4 \mathrm{GHz} \\
1-11\end{array}$ & $\begin{array}{l}1-11 \\
\mathrm{dBm}\end{array}$ & $\begin{array}{l}65-72 \\
\text { Mbps }\end{array}$ \\
\hline
\end{tabular}

Tabel 2. Aplikasi

\begin{tabular}{ccc}
\hline Aplikasi & $\begin{array}{c}\text { Target } \\
\text { Throughput }\end{array}$ & $\begin{array}{c}\text { Airtime/device } \\
(\%)\end{array}$ \\
\hline $\begin{array}{c}\text { Web-browsing/email } \\
\text { (heavy) }\end{array}$ & $1 \mathrm{Mbps}$ & 2,77 \\
Web-browsing/email \\
$\quad \begin{array}{l}\text { (moderate) } \\
\text { Youtube HD 720 }\end{array}$ & $500 \mathrm{Kbps}$ & 1,39 \\
$\begin{array}{c}\text { Youtube Standard } \\
\text { Defenition 360p }\end{array}$ & $2,5 \mathrm{Mbps}$ & 6,93 \\
$\begin{array}{c}\text { Web-browsing/email } \\
\text { (light) }\end{array}$ & $250 \mathrm{Kbps}$ & 2,08 \\
E-learning & $2 \mathrm{Mbps}$ & 0,7 \\
\hline
\end{tabular}


Tahapan kedua adalah tahapan perencanaan dan perancangan penempatan Access Point. Pada tahapan ini digunakan data denah gedung JTE lantai 1 dan lantai 2, denah gedung JAK lantai 1 sampai dengan lantai 3, dan denah gedung JAN lantai 1 sampai dengan lantai 3.

Jenis penghalang yang diperhitung adalah dinding bangunan dan sekat antar ruangan. Dinding utama bangunan terbuat dari beton atau disebut concrete wall, beberapa dinding juga terbuat dari batako (brick wall), dan sekat dalam ruangan terbuat dari gypsum (dry wall). Masing-masing material ini memiliki nilai redaman/attenuasi yang berbeda.

Selanjutnya adalah tahapan analisis hasil perancangan. Masing-masing hasil desain akan dianalisis dan dibandingkan.

\section{A. Cakupan Area}

Cakupan area dari Access Point sangat dipengaruhi oleh keberadaan dinding penghalang. Pemodelan untuk propagasi sinyal Access Point dalam ruangan menggunakan pemodelan multi-wall seperti diilustrasikan pada Gambar 1. Sedangkan untuk persamaan matematisnya seperti pada persamaan (1) [6].

$\operatorname{Lmw}(d)=L o+10 \gamma \log (d)+\sum_{i=1}^{M} L i$

Dimana $L o$ adalah nilai referensi rugi-rugi pada jarak $1 \mathrm{~m}$, yaitu sebesar 40,05 dB. $\gamma$ adalah faktor eksponen pathloss, $d$ adalah jarak dalam satuan meter dan $\mathrm{Li}$ adalah faktor attenuasi dalam satuan $\mathrm{dB}$, dan $M$ adalah jumlah dinding diantara antena pengirim dan penerima. Nilai $L i$ telah diperinci pada Tabel 3.

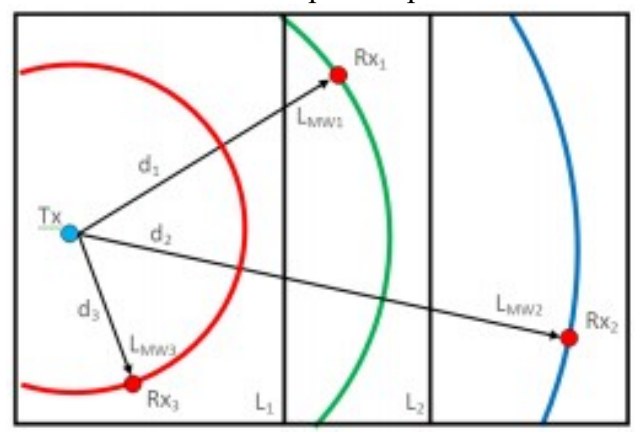

Gambar 2. Ilustrasi Pemodelan Multi-wall

Tabel 3. Jenis Penghalang dan Nilai Attenuasinya

\begin{tabular}{ccc}
\hline No. & Jenis Penghalang & Attenuasi \\
\hline 1 & Concrete Wall & $12 \mathrm{~dB}$ \\
2 & Brick Wall & $10 \mathrm{~dB}$ \\
3 & Dry Wall & $3 \mathrm{~dB}$ \\
\hline
\end{tabular}

\section{B. Kapasitas}

Penempatan Access Point berdasarkan kapasitas harus mempertimbangkan beberapa hal sebagai berikut. a) Kemampuan dari infrastruktur jaringan wireless.

b) Tipe, jumlah, dan kemampuan dari perangkat client [7].

c) Tipe aplikasi yang akan digunakan.

d) Mobilitas pengguna dalam jaringan.

e) Level minimum throughput yang disediakan oleh jaringan.

Berdasarkan kelima poin diatas dapat ditentukan kebutuhan airtime bagi setiap perangkat pengguna berdasarkan aplikasi yang dijalankan, sehingga kebutuhan total Access Point dapat dihitung menggunakan persamaan (2) dan (3) [8].

$$
A R D=\frac{A T}{\operatorname{Max} D T}
$$

dimana:

$$
\begin{array}{ll}
\text { ARD }= & \text { Kebutuhan Airtime setiap } \\
& \text { perangkat } \\
\text { AT } & \text { Throughput aplikasi } \\
\text { Max DT }= & \text { Maksimal throughput setiap } \\
& \text { perangkat }
\end{array}
$$

$$
\text { Total } A P=\sum T D \times A R D
$$

dimana:

$$
\begin{array}{ll}
\text { Total AP } & =\text { Jumlah access point } \\
\text { TD } & =\underset{\text { Kuantitas suatu perangkat }}{\text { pengguna }}
\end{array}
$$

\section{HASIL DAN PEMBAHASAN}

Rancangan penempatan Access Point pada gedung JTE, JAK, dan JAN menggunakan dua skenario, yaitu skenario 1 mempertimbangkan cakupan area saja dan skenario 2 mempertimbangkan cakupan area dan kapasitas. Spesifikasi perangkat Access Point yang digunakan adalah Access Point 121 (802.11n 2x2:2) dengan antena internal dan dual radio. Daya pancar sebesar $18 \mathrm{dBm}$ dan sensitivitas sinyal sebesar -80 $\mathrm{dBm}$ untuk skenario 1 dan $-70 \mathrm{dBm}$ untuk skenario 2 .

\section{A. Skenariol}

a) Gedung Jurusan Teknik Elektro

Ketika merancang penempatan Access Point berdasarkan cakupan area saja, maka posisi penempatan Access Point diatur agar dapat mencakup seluruh area layanan atau area yang diprioritaskan memperoleh sinyal Access Point. Oleh karena itu, beberapa hal yang menjadi pertimbangan dalam skenario ini adalah kondisi fisik bangunan dan jenis materialnya.

Lantai 1 membutuhkan tujuh perangkat Access Point agar semua area mendapatkan sinyal RSSI dari Access Point. Ketujuh Access Point tersebut masing-masing ditempatkan di laboratorium pengukuran, ruang instruktur laboratorium elektronika digital \& mikroprosesor, ruang workshop instalasi, 
koridor bagian selatan, koridor bagian utara, koridor bagian barat, dan ruang staf. Besar nilai RSSI yang terukur dari Access Point berkisar $-35 \mathrm{dbm}$ sampai $-80 \mathrm{dBm}$. Hasil rancangan penempatan Access Point pada lantai 1 gedung JTE dan peta sebaran sinyal RSSI dari masing-masing Access Point ditunjukkan dalam Gambar 3.

Sedangkan lantai 2 membutuhkan delapan (8) perangkat Access Point yang masingmasing ditempatkan di ruang praktek 1, ruang praktek 4, ruang praktek 7 , koridor bagian selatan, ruang theater, koridor bagian utara, ruang staf/rapat, dan ruang seminar.

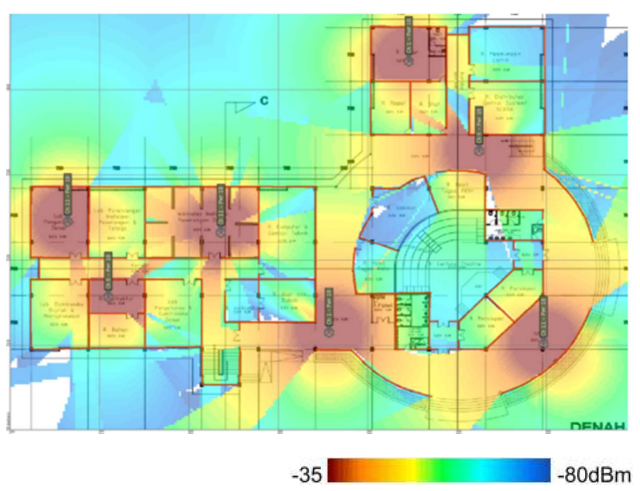

Gambar 3. Peta Sinyal RSSI Lantai 1 Gedung JTE

Besar nilai RSSI yang terukur dari kedelapan Access Point tersebut berkisar -35 $\mathrm{dBm}$ sampai $-80 \mathrm{dBm}$. Hasil rancangan penempatan Access Point pada lantai 2 gedung JTE dan peta sinyal RSSI dari masing-masing Access Point ditunjukkan pada Gambar 4.

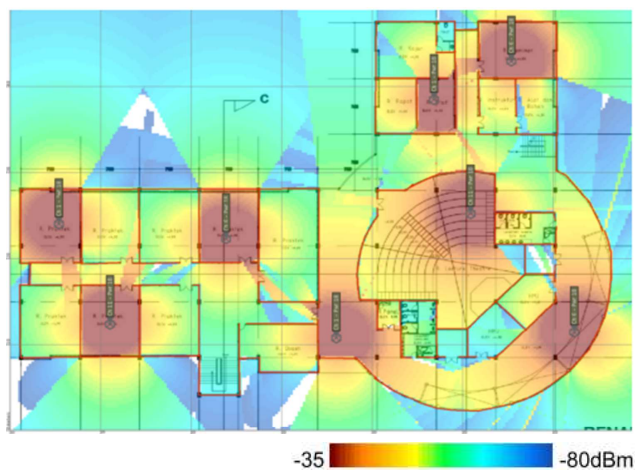

Gambar 4. Peta Sinyal RSSI Lantai 1 Gedung JTE

b) Gedung Jurusan Akuntansi (JAK)

Denah gedung JAK berbeda dengan JTE. JAK terdiri dari 3 lantai. Lantai 1 membutuhkan 6 perangkat Access Point agar semua area mendapatkan sinyal RSSI dari Access Point. Keenam Access Point tersebut masing-masing ditempatkan di ruang pembina kemahasiswaan, ruang staf, ruang koridor selatan, ruang kajur, ruang layanan informasi, dan ruang HMJ. Besar nilai RSSI yang terukur dari Access Point berkisar $-35 \mathrm{dBm}$ sampai -80 $\mathrm{dBm}$. Hasil rancangan penempatan Access Point pada lantai 1 gedung JAK dan peta sebaran sinyal RSSI dari masing-masing Access Point ditunjukkan dalam Gambar 5.

Lantai 2 membutuhkan 7 perangkat Access Point agar semua area mendapatkan sinyal RSSI dari Access Point. Ketujuh Access Point tersebut masing-masing ditempatkan di ruang kelas 1, ruang kelas 2, hall tengah, ruang Dosen, ruang kelas 4, ruang kelas 5, dan ruang case study. Besar nilai RSSI yang terukur dari Access Point berkisar $-35 \mathrm{dBm}$ sampai -80 $\mathrm{dBm}$. Hasil rancangan penempatan Access Point pada lantai 1 gedung JAK dan peta sebaran sinyal RSSI dari masing-masing Access Point ditunjukkan dalam Gambar 6.

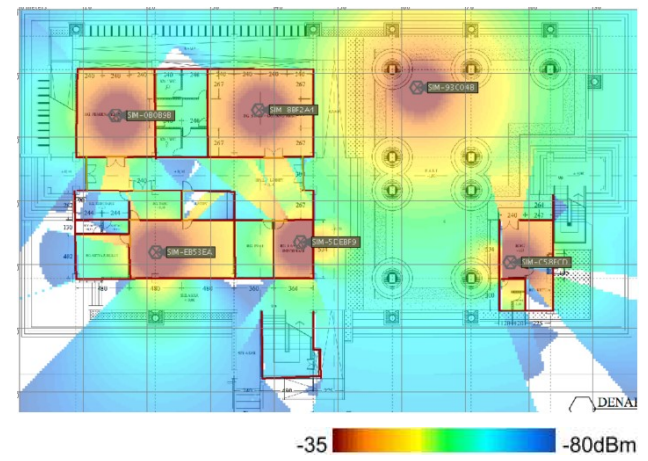

Gambar 5. Peta Sinyal RSSI Lantai 1 Gedung JAK

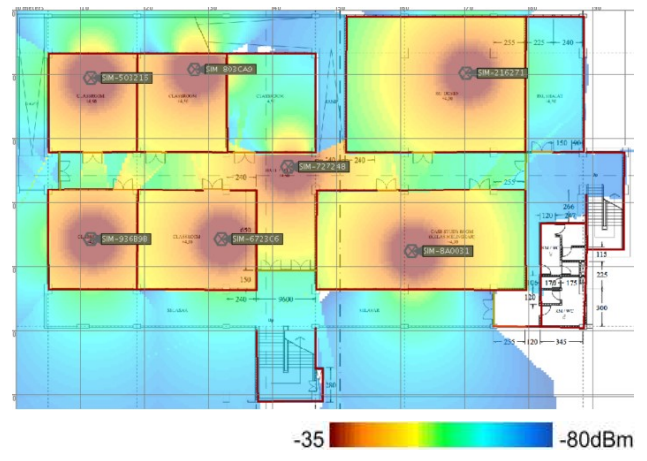

Gambar 6. Peta Sinyal RSSI Lantai 2 Gedung JAK

Selanjutnya, lantai 3 membutuhkan 7 perangkat AP agar semua area mendapatkan sinyal RSSI dari AP. Ketujuh AP tersebut masing-masing ditempatkan di laboratorium bahasa, laboratorium Akuntansi, Hall tengah, ruang Aula mini, laboratorium Komputer, laboratorium Multifungsi, dan laboratorium Multimedia. Besar nilai RSSI yang terukur dari AP berkisar $-35 \mathrm{dBm}$ sampai $-80 \mathrm{dBm}$. Hasil rancangan penempatan AP pada lantai 3 gedung JAK dan peta sebaran sinyal RSSI dari masing-masing AP ditunjukkan dalam Gambar 7. 


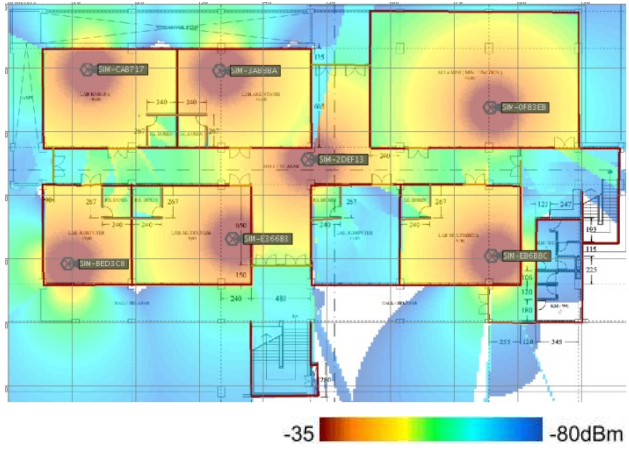

Gambar 7. Peta Sinyal RSSI Lantai 3 Gedung JAK

c) Gedung Jurusan Administrasi Niaga

Karakteristik gedung JAN sangat mirip dengan JAK. Gedung JAN juga terdiri dari 3 lantai. Lantai 1 membutuhkan 6 perangkat AP agar semua area mendapatkan sinyal RSSI dari AP. Keenam AP tersebut masing-masing ditempatkan di hall bagian selatan, ruang Dosen, ruang Staf, ruang HMJ, ruang PRODI, dan ruang Rapat. Besar nilai RSSI yang terukur dari AP berkisar $-35 \mathrm{dBm}$ sampai -80 $\mathrm{dBm}$. Hasil rancangan penempatan AP pada lantai 1 gedung JAN dan peta sebaran sinyal RSSI dari masing-masing AP ditunjukkan dalam Gambar 8.

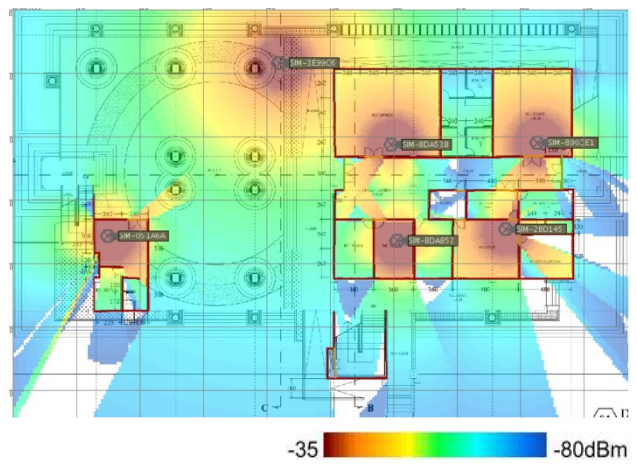

Gambar 8. Peta Sinyal RSSI Lantai 1 Gedung JAN

Lantai 2 membutuhkan 7 perangkat AP agar semua area mendapatkan sinyal RSSI dari AP. Ketujuh AP tersebut masing-masing ditempatkan di ruang kelas 1, ruang kelas 2, ruang kelas 3, ruang kelas 5, ruang case study, ruang kelas 6 , dan ruang kelas 7 . Besar nilai RSSI yang terukur dari AP berkisar $-35 \mathrm{dBm}$ sampai $-80 \mathrm{dBm}$. Hasil rancangan penempatan AP pada lantai 2 gedung JAN dan peta sebaran sinyal RSSI dari masing-masing AP ditunjukkan dalam Gambar 9.

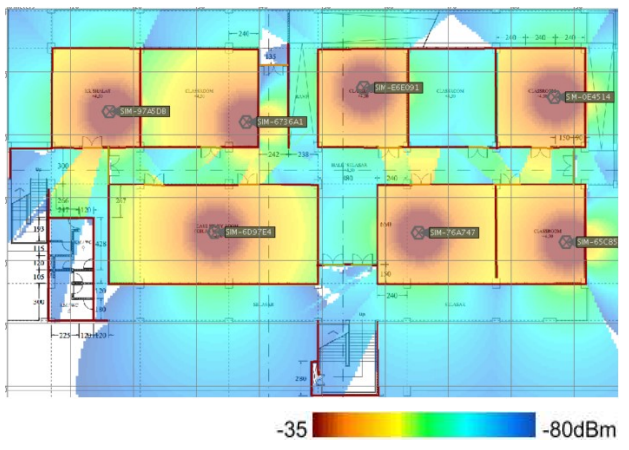

Gambar 9. Peta Sinyal RSSI Lantai 2 Gedung JAN

Selanjutnya, lantai 3 membutuhkan 6 perangkat AP agar semua area mendapatkan sinyal RSSI dari AP. Keenam AP tersebut masing-masing ditempatkan di ruang Aula mini, laboratorium Bahasa, laboratorium Komputer, laboratorium Perkantoran, laboratorium Pengetikan dan laboratorium Manual. Besar nilai RSSI yang terukur dari AP berkisar $-35 \mathrm{dBm}$ sampai $-80 \mathrm{dBm}$. Hasil rancangan penempatan AP pada lantai 3 gedung JAN dan peta sebaran sinyal RSSI dari masing-masing AP ditunjukkan dalam Gambar 10.

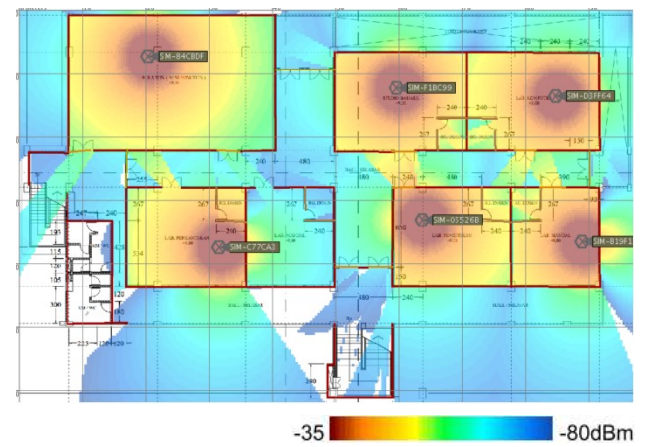

Gambar 10. Peta Sinyal RSSI Lantai 3 Gedung JAN

\section{B. Skenario 2}

Skenario 2 ini mempertimbangkan faktor cakupan area dan kapasitas. Berbeda dengan skenario 1. Pada skenario 2 ini selain mempertimbang kondisi fisik bangunan juga mempertimbangkan jumlah, jenis, dan kemampuan perangkat pengguna, serta aplikasi yang akan digunakan.

Berdasarkan hasil pada tahapan analisis kebutuhan, diperoleh data jumlah pengguna dan jenis aplikasi yang akan dijalankan pada jaringan wifi. Oleh karena itu, dilakukan perhitungan jumlah AP yang dibutuhkan dalam desain menggunakan formula 2, sehingga diperoleh data kebutuhan AP pada gedung JTE seperti pada Tabel 4. 
ISSN : 2085-3688; e-ISSN : 2460-0997

Desain Jaringan WLAN Berdasarkan Cakupan Area dan Kapasitas

Tabel 4. Data Kebutuhan AP Pada Gedung JTE

\begin{tabular}{|c|c|c|c|c|}
\hline $\begin{array}{c}\text { Model } \\
\text { Perangkat }\end{array}$ & $\begin{array}{c}\text { Jumlah } \\
\text { Perangkat }\end{array}$ & Aplikasi & $\begin{array}{c}\text { Airtime/ } \\
\text { perangkat }\end{array}$ & $\begin{array}{c}\text { Jumlah } \\
\text { AP }\end{array}$ \\
\hline Netbook & 120 & $\begin{array}{c}\text { Web- } \\
\text { browsing/ } \\
\text { email } \\
\text { (moderate) }\end{array}$ & $1,39 \%$ & 1,67 \\
\hline \multirow{4}{*}{ Laptop } & 150 & $\begin{array}{l}\text { Web- } \\
\text { browsing/ } \\
\text { email } \\
\text { (heavy) }\end{array}$ & $2,77 \%$ & 4,15 \\
\hline & 75 & $\begin{array}{l}\text { Youtube } \\
\text { HD } 720\end{array}$ & $6,93 \%$ & 5,19 \\
\hline & 85 & E-learning & $5,55 \%$ & 4,71 \\
\hline & 150 & $\begin{array}{l}\text { Web- } \\
\text { browsing/ } \\
\text { email } \\
\text { (light) }\end{array}$ & $0,7 \%$ & 1,05 \\
\hline \multirow{3}{*}{$\begin{array}{l}\text { Smart } \\
\text { phone }\end{array}$} & 100 & $\begin{array}{c}\text { Web- } \\
\text { browsing } \\
\text { /email } \\
\text { (moderate) }\end{array}$ & $1,39 \%$ & 1,39 \\
\hline & 75 & $\begin{array}{c}\text { Youtube } \\
\text { Standard } \\
\text { Defenition } \\
360 \mathrm{p}\end{array}$ & $2,08 \%$ & 1,56 \\
\hline & & & Total AP & 19,72 \\
\hline
\end{tabular}

Hasil analisis kebutuhan JAK dan JAN tidak jauh berbeda, sehingga kebutuhan AP juga tidak berbeda. Kebutuhan AP JAK dan JAN dirinci pada Tabel 5.

Tabel 5. Data Kebutuhan AP Pada Gedung JAK dan JAN

\begin{tabular}{|c|c|c|c|c|}
\hline $\begin{array}{c}\text { Model } \\
\text { Perangkat }\end{array}$ & $\begin{array}{c}\text { Jumlah } \\
\text { Perangkat }\end{array}$ & Aplikasi & $\begin{array}{c}\text { Airtime/ } \\
\text { perangkat }\end{array}$ & $\begin{array}{c}\text { Jumlah } \\
\text { AP }\end{array}$ \\
\hline Netbook & 350 & $\begin{array}{c}\text { Web- } \\
\text { browsing/e } \\
\text { mail } \\
\text { (moderate) }\end{array}$ & $1,39 \%$ & 4,87 \\
\hline \multirow{4}{*}{ Laptop } & 50 & $\begin{array}{c}\text { Web- } \\
\text { browsing/e } \\
\text { mail } \\
\text { (heavy) }\end{array}$ & $2,77 \%$ & 1,39 \\
\hline & 50 & $\begin{array}{c}\text { Youtube HD } \\
720\end{array}$ & $6,93 \%$ & 3,47 \\
\hline & 175 & E-learning & $5,55 \%$ & 9,71 \\
\hline & 150 & $\begin{array}{c}\text { Web- } \\
\text { browsing/e } \\
\text { mail } \\
\text { (light) }\end{array}$ & $0,70 \%$ & 1,05 \\
\hline $\begin{array}{l}\text { Smart } \\
\text { phone }\end{array}$ & 200 & $\begin{array}{c}\text { Web- } \\
\text { browsing } \\
\text { /email } \\
\text { (moderate) }\end{array}$ & $1,39 \%$ & 2,78 \\
\hline
\end{tabular}

\begin{tabular}{ccccc}
\hline $\begin{array}{c}\text { Model } \\
\text { Perangkat }\end{array}$ & $\begin{array}{c}\text { Jumlah } \\
\text { Perangkat }\end{array}$ & Aplikasi & $\begin{array}{c}\text { Airtime/ } \\
\text { perangkat }\end{array}$ & $\begin{array}{c}\text { Jumlah } \\
\text { AP }\end{array}$ \\
\hline 75 & $\begin{array}{c}\text { Youtube } \\
\text { SD 360p }\end{array}$ & $2,08 \%$ & 1,56 \\
& & & Total AP & $\mathbf{2 4 , 8 2}$ \\
\hline
\end{tabular}

a) Gedung Jurusan Teknik Elektro

Berdasarkan data yang diuraikan pada Tabel 4 diketahui jumlah AP yang akan ditempatkan pada gedung JTE adalah sebanyak 19,72 atau sama dengan 20 buah AP yang dibagi menjadi 9 buah untuk lantai 1 dan 11 buah untuk lantai 2.

Kesembilan AP yang disebar di lantai 1 ditempatkan di laboratorium Pengukuran, ruang Workshop instalasi, laboratorium Elektronika digital \& mikroprosesor, laboratorium Pengukuran \& elektronika dasar, koridor bagian timur laut, koridor bagian barat daya, koridor bagian selatan, ruang Staf, dan ruang Distributed Control System SCADA. Besar nilai RSSI yang terukur dari AP berkisar $-35 \mathrm{dBm}$ sampai $-70 \mathrm{dBm}$. Sinyal RSSI dari masing-masing AP pada lantai 1 ditunjukkan dalam Gambar 11.

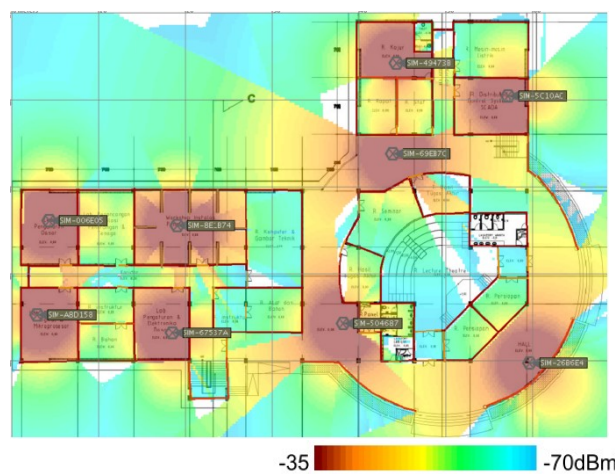

Gambar 11. Peta Sinyal RSSI Lantai 1 JTE

Pada lantai 2 ditempatkan 11 AP. Kesebelas AP tersebut masing-masing ditempatkan di ruang Praktek 2, ruang Praktek 4, ruang Praktek 6, ruang Praktek 8, ruang Dosen, koridor bagian timur, ruang Theater, koridor bagian barat laut, koridor barat daya, ruang Staf/Rapat, dan ruang Seminar. Besar nilai RSSI yang terukur dari kesebelas AP tersebut berkisar $-35 \mathrm{dBm}$ sampai $-70 \mathrm{dBm}$. Pola sinyal RSSI dari masing-masing AP pada lantai 2 ditunjukkan dalam Gambar 12. 


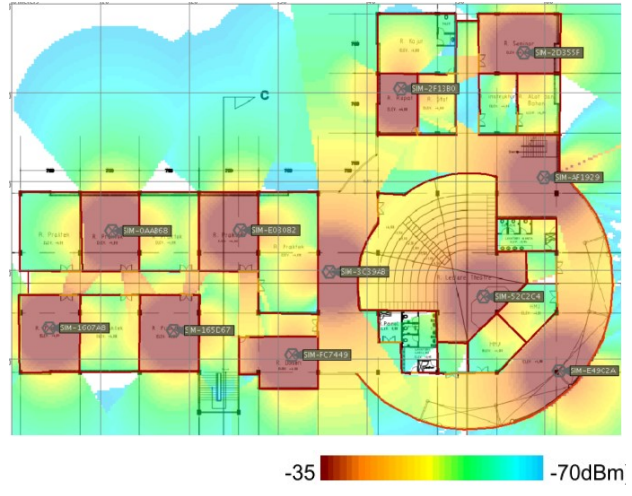

Gambar 12. Peta Sinyal RSSI Lantai 2 JTE

b) Gedung Akuntansi

Berdasarkan data yang diuraikan pada Tabel 5 diketahui jumlah AP yang akan ditempatkan pada gedung JAK sebanyak 24,82 atau sama dengan 25 buah AP yang dibagi menjadi 7 buah untuk lantai 1,9 buah untuk lantai 2, dan 9 buah untuk lantai 3 .

Ketujuh AP yang disebar di lantai 1 ditempatkan di ruang Pembina kemahasiswaan, ruang Staf, hall bagian selatan, ruang Kajur, ruang Tamu, ruang Layanan informasi, dan ruang HMJ. Besar nilai RSSI yang terukur dari AP berkisar -35 $\mathrm{dBm}$ sampai $-70 \mathrm{dBm}$. Sinyal RSSI dari masing-masing AP pada lantai 1 ditunjukkan dalam Gambar 13.

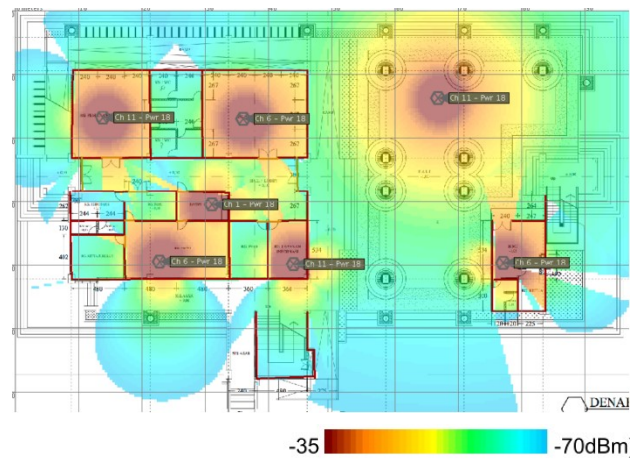

Gambar 13. Peta Sinyal RSSI Lantai 1 JAK

Pada lantai 2 ditempatkan 9 AP. Kesembilan AP tersebut masing-masing ditempatkan di ruang Kelas 1, ruang Kelas 2, hall tengah, ruang Dosen, ruang Kelas 4, ruang Kelas 5, hall bagian utara, ruang case study, dan hall bagian barat. Besar nilai RSSI yang terukur dari kesembilan AP tersebut berkisar $35 \mathrm{dBm}$ sampai $-70 \mathrm{dBm}$. Pola sinyal RSSI dari masing-masing AP pada lantai 2 ditunjukkan dalam Gambar 14.

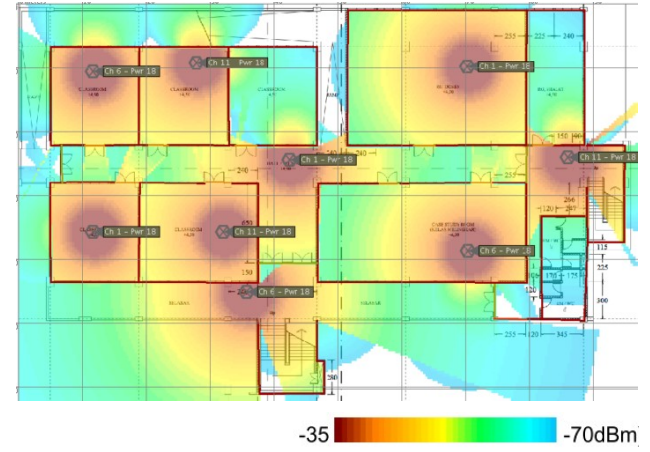

Gambar 14. Peta Sinyal RSSI Lantai 2 JAK

Pada lantai 3 juga ditempatkan 9 AP. Kesembilan AP tersebut masing-masing ditempatkan di laboratorium Bahasa, laboratorium Akuntansi, Hall tengah, ruang Aula mini, laboratorium Komputer, laboratorium Multifungsi, hall bagian utara, laboratorium Komputer, dan laboratorium Multimedia. Besar nilai RSSI yang terukur dari kesembilan AP tersebut berkisar $-35 \mathrm{dBm}$ sampai $-70 \mathrm{dBm}$. Pola sinyal RSSI dari masing-masing AP pada lantai 3 ditunjukkan dalam Gambar 15.

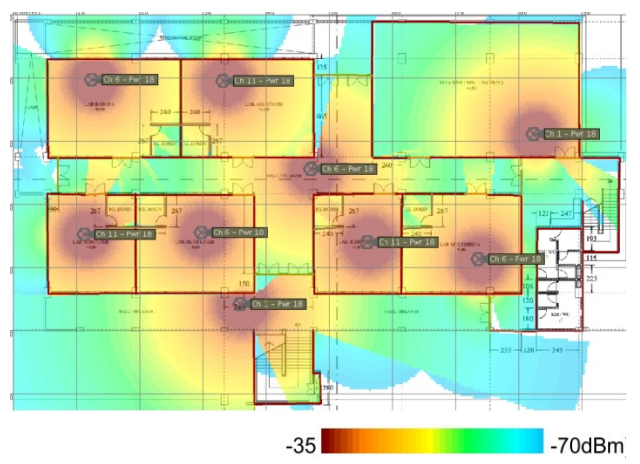

Gambar 15. Peta Sinyal RSSI Lantai 3 JAK

c) Gedung Adminstrasi Niaga

Berdasarkan data yang diuraikan pada Tabel 5 diketahui jumlah AP yang akan ditempatkan pada gedung JAN sebanyak 24,82 atau sama dengan 25 buah AP yang dibagi menjadi 7 buah untuk lantai 1,9 buah untuk lantai 2, dan 9 buah untuk lantai 3. Desain penempatan AP pada gedung JAN tidak jauh berbeda dengan JAK.

Ketujuh AP yang disebar di lantai 1 ditempatkan di hall bagian selatan, ruang Dosen, ruang Staf, ruang HMJ, ruang PRODI, ruang Tamu, dan ruang Rapat. Besar nilai RSSI yang terukur dari AP berkisar $-35 \mathrm{dBm}$ sampai $-70 \mathrm{dBm}$. Sinyal RSSI dari masingmasing AP pada lantai 1 ditunjukkan dalam Gambar 16. 
ISSN : 2085-3688; e-ISSN : 2460-0997

Desain Jaringan WLAN Berdasarkan Cakupan Area dan Kapasitas

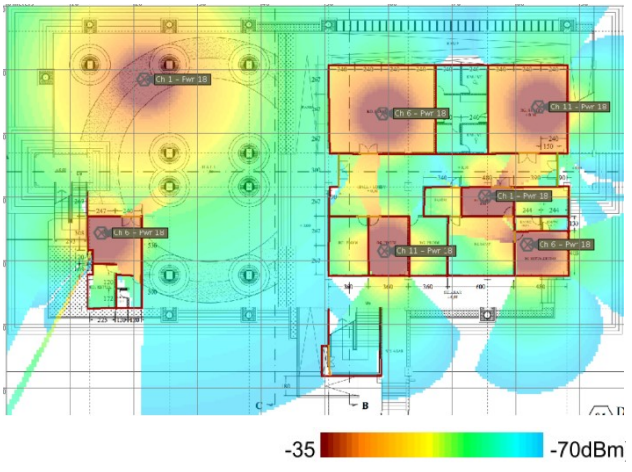

Gambar 16. Peta Sinyal RSSI Lantai 1 JAN

Pada lantai 2 ditempatkan 9 AP. Kesembilan AP tersebut masing-masing ditempatkan di ruang Kelas 1, ruang Kelas 2, ruang Kelas 3, ruang Kelas 4, ruang Kelas 5, ruang Case study, hall bagian utara, ruang Kelas 6, dan ruang Kelas 7. Besar nilai RSSI yang terukur dari kesembilan AP tersebut berkisar $-35 \mathrm{dBm}$ sampai $-70 \mathrm{dBm}$. Pola sinyal RSSI dari masing-masing AP pada lantai 2 ditunjukkan dalam Gambar 17.

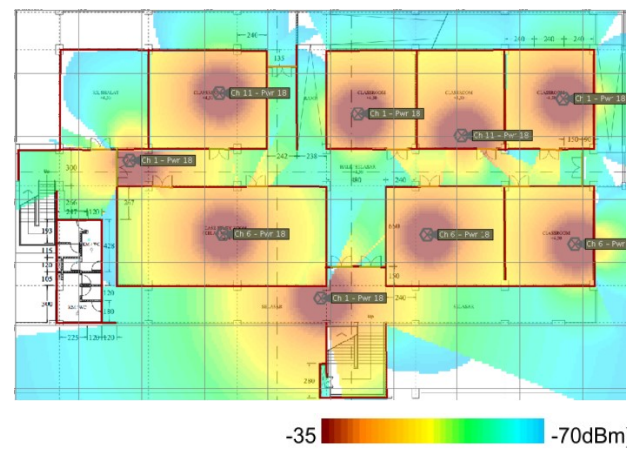

Gambar 17. Peta Sinyal RSSI Lantai 2 JAN

Pada lantai 3 juga ditempatkan 9 AP. Kesembilan AP tersebut masing-masing ditempatkan di ruang Aula mini, hall bagian tengah, laboratorium bahasa, laboratorium Komputer, laboratorium perkantoran, laboratorium Manual 1, hall bagian utara, laboratorium Pengetikan dan laboratorium Manual 2. Besar nilai RSSI yang terukur dari kesembilan AP tersebut berkisar $-35 \mathrm{dBm}$ sampai $-70 \mathrm{dBm}$. Pola sinyal RSSI dari masing-masing AP pada lantai 3 ditunjukkan dalam Gambar 18.

Perbandingan hasil desain jaringan wireless menggunakan AP pada skenario 1 dan skenario 2 ditunjukkan pada Tabel 6 .
Tabel 6. Perbandingan Jumlah AP Skenario1 \& 2

\begin{tabular}{|c|c|c|c|}
\hline \multirow{2}{*}{$\begin{array}{c}\text { Area } \\
\text { Penempatan }\end{array}$} & \multicolumn{2}{|c|}{ Jumlah AP } & \multirow{2}{*}{$\begin{array}{c}\text { SK1 } \div \text { SK2 } \\
(\%)\end{array}$} \\
\hline & $\begin{array}{c}\text { Skenario } \\
1 \text { (SK1) }\end{array}$ & $\begin{array}{c}\text { Skenario } \\
2 \text { (SK2) }\end{array}$ & \\
\hline Gedung JTE & 15 & 20 & 75,00 \\
\hline Gedung JAK & 20 & 25 & 80,00 \\
\hline \multirow[t]{2}{*}{ Gedung JAN } & 19 & 25 & 76,00 \\
\hline & \multicolumn{2}{|c|}{ Total rerata $(\%)$} & 77,00 \\
\hline
\end{tabular}

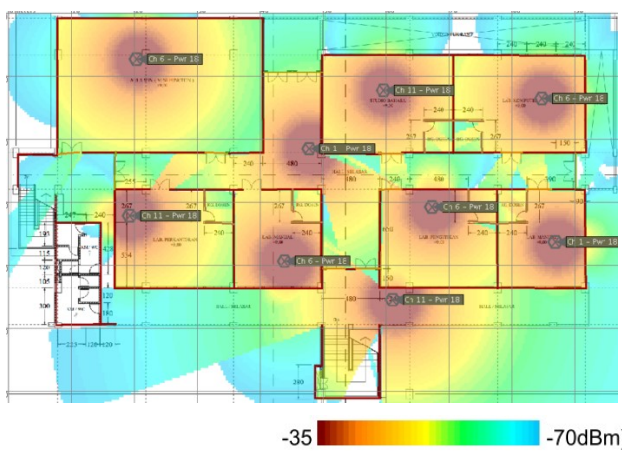

Gambar 18. Peta Sinyal RSSI Lantai 3 JAN

Hasil rancangan penempatan AP pada skenario 1 membutuhkan 15 buah AP untuk JTE, 20 buah AP untuk JAK, dan 19 buah AP untuk JAN. Sedangkan pada skenario 2 membutuhkan 20 buah AP untuk JTE, 25 buah AP untuk JAK, dan 25 buah AP untuk JAN. Hasil ini menunjukkan bahwa dalam perancangan penempatan AP pada Kampus 2 PNUP sebaiknya mempertimbangkan cakupan area dan kapasitas, karena rancangan yang hanya mempertimbangkan cakupan area saja hanya dapat memenuhi 77,00\% kebutuhan AP.

\section{PENUTUP}

\section{A. Kesimpulan}

Kesimpulan pada penelitian ini adalah.

1. Desain jaringan WLAN berdasarkan cakupan area dan kapasitas pada kampus 2 PNUP menggunakan Access Point sebanyak 20 buah AP untuk JTE, 25 buah AP untuk JAK, dan 25 buah AP untuk JAN.

2. Desain jaringan WLAN sebaiknya mempertimbangkan cakupan area dan kapasitas, karena desain yang mempertimbangkan cakupan area saja hanya dapat memenuhi 77\% kebutuhan AP.

\section{DAFTAR PUSTAKA}

[1] Surjati I., Chandra H., Prabowo A., "Analisis Sistem Integrasi Jaringan WiFi dengan Jaringan GSM Indoor pada Lantai Basement Balai Sidang Jakarta Convention Centre", JETri, Vol. 7, No. 1, Hal 1-16, Agustus 2007.

[2] Saharuna Z., Widyawan, Sumaryono S., "Deployment jaringan sensor nirkabel berdasarkan algoritma 
particle swarm optimization", Conference on Information Technology and Electrical Engineering (CITEE), 2012.

[3] Yeong, Shoa-Yei, "Indoor WLAN Monitoring and Planning using Empirical and Theoretical Propagation Models", Universiti Sains Malaysia, 2010.

[4] Widyaningsih B, dkk., "Optimasi Area Cakupan Jaringan Nirkabel Dalam Ruangan (Studi kasus: PTIIK Universitas Brawijaya)", Universitas Brawijaya, 2011.

[5] Nurwarsito H, Amron K, dan Widyaningsih B, “ Wifi Network Design for High Performance", International
Conference on Engineering and Technology Development (ICETD), hal. Phil. Trans. Roy. Soc. London, vol. A247, pp. 161-166, 2013.

[6] Riza M. F., Santoso I., Zahra A.A.,'Simulasi Cakupan Area Sinyal WLAN 2,4 GHz pada Ruangan”, 2012.

[7] Fajar F, "Perencanaan Coverage Indoor Wireless Local Area Network (WLAN) di Hotel Graha Petrokimia Gresik". 2010.

[8] Nagy A. V., "Aerohive Design \& Configuration Guide High-Density Wi-Fi", Aerohive Networks, Inc., Sunnyvale, 2012. 